\title{
THE DARK SIDE OF GENDER EQUALITY SCHEMES IN MANAGEMENT - A DEEP DIVE INTO A GERMAN AUTO MANUFACTURER
}

Despite the wide array of corporate programmes and the increased attention to fight gender inequality issues, efforts have brought about only timid results, in particular in management (Catalyst, 2018). What reason account for the stalled progress and what can be done?

By examining gender equality interventions in a masculine organisation; and mobilizing men's and women's perceptions related to gender equality in management, this article seeks to provide deeper insights on the mechanisms of gender equality change in organisation. A qualitative case study comprising document analysis and semi-structured interviews was conducted at an automotive company's headquarter between 2012 and 2015 in Germany and relies on an innovative combination of two analytical frameworks elaborated by Ely and Meyerson (2000) and Rao and Kelleher (2005).

The study shows the limits of formal and systemic gender policy in organisation for it leaves the deep ingrained informal values untouched. The interviewed female managers tend to not subscribe to these programmes. Male managers express resentment against not only the corporate actions but also against gender quota. Both male and female managers firmly believe in the meritocratic system and take for granted the gendered order of their organisation.

Keywords: gender, diversity, management, organisation, equal opportunity

$\mathrm{A}$ both the top and the bottom of the employment pyramid, women continue to lag behind men in terms of pay and authority, despite closing gender gaps in educational attainment and workplace seniority.

Consequently, governments in Europe have taken radical action to tackle these persistent disparities, pushing thus many large-scale organisations to implement a variety of actions aiming at increasing the number of women in their management ranks. Are these programmes a real chance or a trap for women? How are they designed? How do male managers view these programmes? How do they affect the gender relations in the workplace and in particular in management?

Recent scholarship shows that while there have been successes in fighting overt discrimination and gender inequalities in the organisations, equality actions in organisations are often marginalized, with the result that ownership and responsibility for equality on the part of all employees is low, and the impact of equality action on the whole organization is limited (Hearn et al., 2010).

In this context, this paper attempts to contribute to a better understanding of what Radjavi (2012) calls "the social life" of gender policies. Radjavi (2012) argues that one's approach to achieving gender equity in management does not suit all countries, organisations, or even business units within organisations. Hence gender equality schemes in management are a product of a certain time and a certain place. Following this line or argument, this paper bridges the macro-, the meso- and the micro levels by using a case study in a German automotive company. In the recent years, the German, if not the European automobile sector at large, has been sharply criticized for remaining a masculine corporate environment, despite gender equality measures.

This article examines thus the local organising of gender equity and takes into account (1) the environmental factors influencing the design of these actions (macro-level); (2) re- veals discrepancies or matches between the espoused theoretical formulations and the practice of gender equality in the German automotive company (meso-level), and (3) directs attention on the voices of female and male managers working in the selected Germany automotive company (micro-level).

The rest of the paper is organised as follows: the next section reviews the literature, on advancing gender equality change in the organisation and sets the theoretical framework informing the study. The second section offers an overview of the gender equality context in Germany for its plays a key role when designing organisational gender equality schemes. The third section outlines the methodology used in this research. The fourth section presents and discusses the key findings. The paper ends with reflections for further research.

\section{Theoretical background Gender work and organisation}

The field of "gendered organisations studies" has expanded over the last decades and explored the different and often hidden ways women are subordinated (Acker, 1990, 1992; Wajcman, 1998; Connell, 2002; Gherardi - Poggio 2007; Calás - Smircich, 2006; 2009; Lewis - Simpsons, 2010; Hanappi-Egger - Eberherr, 2016). Moreover it criticized the way organisational and management studies just ignored the question of gender (Acker, 1992), maintaining thus crying disparities and hindering access to opportunities and resources in the organisation.

One starting point to explain this paradox is Acker's contribution (2006) which argues that gender is a constitutive and organizing principle of every organization and reflects wider societal inequalities. This means that companies wishing to tackle gender inequality nonetheless continue to reproduce inequalities unconsciously because the whole organization of society is already 'gendered'. In other words, the gender substructure of organizations 
(Acker, 1992, p. 252.) is inherently linked to the gender relations in other parts of the society (Acker, 1992, p. 259.).

Acker locates the gender substructure as its name indicates, in hidden gender displays and processes perpetuating gender asymmetry for that they are viewed and disseminated as gender neutral or natural, hence taken for granted by the individuals in the organisation. While overt gender practices such as masculine work culture are easy to detect, gender as structural instrument of stratification may be deeply hidden in organizational processes. The outcomes are covered by rhetoric of objectivity considered universal. Hence, the gendered substructure of an organisation as it is coined by Acker (1990) is located in the arrangement of work, in the rules prescribing behaviour, and in the relations linking work life to social life. Acker (1992) stresses the linkage between the public and private sphere enacted in the figure of the organisation.

Along this differentiation, the gendered substructure creates two polarised and mutually exclusive types of workers embodied by alternatively by men and women. Men enact the ideal worker who fits in the organisational mould and is active in the valued public sphere. Women are at best denigrated in the public sphere, or confined in the private arena. They have other expectations to comply with, such as childbearing. Following this line of argument, the exclusion of women is crucial to ensure the privilege of men. Modern organisations, managerial jobs and successful careers developed on the assumption that workers have no private commitments, organisations value a form of professional commitment that is impossible or with sacrifices for women to attain (Acker, 1990, 1992; Rao - Kellerher, 1999).

By understanding the gender substructure of an organisation, collective and comprehensive actions for gender equality can be better formulated, can dispute existing order and have more sustainable effects. Similarly, Britton (2000) stresses the importance of contextualising the gendered processes in order to efficiently tackle the sources of inequality, destabilise the gender substructure and bring about substantial organisational change.

Likewise, Fagenson's (1993) Gender Organisation Systems approach (GOS) argues that individuals and organisation cannot be understood separately from the society or culture in which they function. Fagenson (1993) posits that the person and organisation centred perspectives are insufficient to fully explain the low representation of women in managerial ranks. The actual situation of women in management is the result of complex interactions between various determinants, such as individual behaviour, organisational policies, societal beliefs and governmental regulations. This also explains why the situation of women in management varies greatly between countries.

Hence, the present study follows the assumptions of GOS approach. Behaviour and attitudes in organisations are the result of the continuous and fluctuant interaction between person characteristics (gender, but also race, age, class...), work situations, organisational structures and practice and the surrounding social systems. This statement reminds Acker's concept of gender substructure linking private and public, and the gendered processes having impact on structural, symbolic, individual and interactional dimensions. All factors such as characteristics of people, work and organisational situations and social systems not only jointly influence women in management, but are to be viewed as intertwined determinants of women's career evolution in management positions.

Hence, there is among feminists a common consensus about the key role of institutions when studying gender (in) equality (Acker, 1990; Fagenson, 1993; Rao - Kelleher, 2003). Rao and Kelleher (2003) precise that institutions differ from "organisations", for they are constituted of rules (formal and informal) maintaining women's positions in societies.

According to Waylen (2014) changing institutions is therefore a fundamental part of lessening gender inequality. The gender dynamics of institutions are often the result of political compromise, the manifestation of existing power relations. Many institutional rules in Europe are now formally gender neutral. For instance non-discrimination decrees on employment, political participation and education are now well established in the European nations, but a huge array of informal rules about gender, such as dress codes and the sexual division of labour, remain. Waylen argues that gendered informal rules interact and co-exist with formal rules, informal institutions often pass unnoticed as they run in parallel to formal rules. The mixture of informal and formal rules are often part of the definition of gender equality initiatives in organisation.

\section{Notions of gender equality}

In order to better grasp the notion of gender equality, Judy Wajcman (1998) in her book on gender and management in the UK provides a review of the historical development of the concept of equal opportunity policies examining both their theoretical and practical background, and their consequences. Her investigation is based on a comparative analysis of male and female senior managers in the UK headquarters of 5 multinational corporations operating in high technology sectors. She gives a detailed overview about two different approaches, the first based on sameness and the second on the notion of difference. She claims that equal opportunity actions in the form they currently bear "draw mostly on the equal treatment/sameness notion of equality" (Wajcman, 1998, p. 16.).

The major problematic is that women are always related to men, designated as deviant from the reference men, it ignores the fact that women are situated differently; this very difference causes the women to be penalized. In a case study approach to examine the interaction between formal equal opportunity employment policies and the extent to which organisational processes continue to obstruct women's career advancement, Wajcman (1999) observed that the construction of managerial job remains universally male. The very concept of managerial career with its hierarchical model of continuous service and regular promotion progress is gendered. She concluded that "to achieve positions of power, women must accommodate themselves to the organization, not the other way around ... Even after two decades of equal opportunity policies, women are still expected to "manage like a man" (Wajcman, 1998, p. 160.). 
Whereas the current equal opportunities initiatives draw largely on the notion of equal treatment/sameness, which mean assimilation to a pre-existing male norm, recent attempts to accommodate women's needs and ensure same opportunities in the workplace show the limitations of the model and the need for further approach of gender equality.

This movement towards new conceptualisation of gender equality is labelled by Holvion and Kamp (2009) as Managing Diversity". At the heart is the idea that differences should be recognized rather than denied or diluted (Liff - Wajcman, 1996). There is a move away from the idea that different groups should be assimilated to meet an organizational norm. Difference is thus viewed positively (Liff - Wajcman, 1996). However, in some circumstances then, rather than being empowering, the 'difference' or diversity approach can be disempowering, dissolving collective identity and strength, in particular women's voices through a focus on diversity and inclusion agenda (Broadbridge - Simpson, 2011). One argument is that women may be seen as less attractive employees if their needs are stressed. Another relevant point is that men may see women as benefiting of special treatment; this will lead to resentment (Hearn, 2012).

\section{Analytical framework: Fourfold framework}

In order to make sense of the gender equality schemes in the German company, the "fourfold framework" of gender equality change in organisation elaborated by Ely and Meyerson (2000) capturing the multifaceted dimension about gender issues in the workplace serves here as main analytical tool for conducting the present study. Indeed, Ely and Meyerson's (2000) and followed by Fletcher and Ely's (2003) empirical based research led to the elaboration of four approaches or "frames" for understanding what gender is and why gender based inequality in organisational setting persists. According to this "fourfold framework", Ely and Meyerson argue that the first three frames are the most used approach to achieve gender equality in organisations nowadays.

Within the frame "Fix the Women" differences of socialisation and skills are the cause of gender issues, women need to be trained to do "as good as men". The "Equal Opportunity" frame is essentially policy based and aims at correcting asymmetry in terms of outcomes by reducing the barriers women have to overcome. Formalised hiring procedure, neutral job description and differentiated targets are typical measures under this frame. Alternatively the frame "Celebrate the Difference" calls for the acceptance of diverse standpoints, and in particular, the appreciation of feminine attributes of management such as inclusiveness and collaboration.

While interventions within these frames have proven significant gains for women, the overall progress is limited. The major problem lies in the fact that women are located as source of gender inequality, this view of gender cor- responds to the essential differential assigned to men and women. Structures and processes remain unquestioned.

According to Ely and Meyerson (2000b), the fourth frame instead provides a more complex approach to understanding and conceptualizing gender. The "Revise the work culture" frame implies the change of deep structure of gender beliefs and unconscious bias that pervade every layer of the organisation and maintain the unequal gender order (Meyerson - Kolb, 2000). Among others, the fourth frame implies the dismantling of dominant discourse of masculinity underpinning managerial and organisational practices.

Drawing directly on the fourfold frame approach presented above, Rao and Kelleher's (1999, 2005) comprehensive work on organisational change in terms of gender equality completes Ely and Meyerson's fourfold framework. As a result, the four frames can be further categorised within four range of actions and impacts; whether it targets formal or informal structures and whether it achieves individual or systemic change. With the combination of both analytical frameworks, the analysis of gender equality schemes is improved in terms of accuracy and practicability, for it enables the identification of potential area of change and goes beyond the sole description of gendered barriers. Acker's (1990) gender substructure and Fagenson's (1993) GOS theory remain of paramount importance to examine a gendered organisation and understand women's position in management. These theories are embedded in the analytical framework (see Figure 1. Multi-layered theoretical framework). The key line of inquiry in this article is to understand in a context dominated by the gender cage (Hanappi-Egger - Eberherr, 2016), how gender equality programmes in management are located and perceived in the selected German organisation.

\section{Gender context in Germany Socio-economic context for gender equality}

As political, economic and institutional contexts are likely to account for various models of gender equality in organizations (Acker, 2006; Tatli et al., 2012), it is crucial to briefly present the economic and social factors as well as the regulations regarding gender in Germany. An overview of the situation of women in the German automotive sector is provided.

The gender context in Germany is characterized by a paradoxical situation. While the general participation rate of women in the German labour market at the time of study was high $(67.7 \% \text { vs } 77.3 \% \text { for men })^{1}$, largely explained by the push effect of the high rate of female employees working part-time (45,1 vs. 31.6\% EU-27 average), the unadjusted gender pay gap exceeds the EU-27 average significantly. Indeed, in Germany, women earned $23 \%$ less than men in 2013, the third biggest in Europe according to Eurostat. In addition, the general participation of women after childbirth drops drastically, which shows that child rearing still affects women's employment patterns.

${ }^{1}$ Source for statistical data (unless stated otherwise) Eurostat Labour Force Survey LFS 2013 (data from 2012). 
The current work context in Germany displays entrenched gender inequalities. This is reflected in a plethora of negative and disproportionate expectations for women to reconcile household and work tasks, persistent gender-based earnings differentials, sex typing of jobs, women's underrepresentation in managerial positions (Cooke, 2007).

This phenomenon can be rooted to the historical development in Germany since the World War II, by the fact that Germany is more conservative socially than other western countries (Holst, 2010). However, the reforms adopted by Germany since the reunification, and in particular after 2005, represent a radical departure from traditional norms (Fagnani - Math, 2007). Income related paid parental leave (Elterngeld) has been implemented, childcare facilities have been extended and since August 2013, a legal entitlement to public childcare for children more than one year old has been introduced. In 2016 gender quota came into force for German companies.

But real progress has been hindered by the institutional framework which still remains very ambiguous and inconsistent as regards the role of women (Weinkopf, 2014). In fact, in recent years the duration of financial support by the husband after divorce has been reduced and mothers are expected to take up paid work earlier than before. Joint taxation for married couples is under debate and the particular German institution of mini-jobs is assessed as rather outdated.

\section{Women in the German automobile industry}

The automotive industry is the largest industry sector in Germany. In 2013, the automobile sector recorded a turnover of EUR 361 billion - around 20 percent of total German industry revenue. The automobile industry is one of the largest employers in Germany, with a workforce of around 756,000, 1/3rd of all manufacturing jobs in Germany (VDA, 2013). Yet only 14\% of the overall workforce is comprised of women (auto manufacturers and suppliers); at the auto manufacturers ${ }^{2}$ only $12 \%$ of the jobs were held by women. The German automotive industry is a male bastion. Women's income is approximately $9 \%$ to $14 \%$ lower than men's income. The difference is sharper at the bottom and the top ends of the employment pyramid, suggesting the existence of what the literature calls the „sticky floor" and ,the glass ceiling” effects. The relatively high salaries in the automotive sector compared to other industries maintain the ,breadwinner model": men work while their wives or partners work less hours, in a household with children under the age of 18 . As a result, the part time model is preferred by female employees. $2 / 3$ of the part time workers are women. The temporary contract is also another growing type of emploment among women in the sector. Temporary and part time roles may offer more flexibility for women to fulfill their caring responsibilities seeing the lack of infrastrcuture and meet social expectations but their precarious status may put them at a poverty risk in the long run (i.e. pensions...).
Despite the effort to motivate women to choose a career in the automotive field, statistics indicate a lack of sustainable change over the past years so that the number of female experts in the automotive organisations remains low (Kurz, 2006). The search for highly qualified professionals may constitute a chance for women, which privileges young graduates at an entry level only; they do not tackle the issue of the "leaking pipeline" and the gendered status quo of the organisation. In fact, only $18.3 \%$ of managerial positions are held by women. The share of women in executive and supervisory boards is even lower with only $5 \%{ }^{3}$. Women with mid-level qualifications in particular in assistance and administrative functions have little opportunity for advancement: they gravitate to traditional female jobs in the peripheral divisions such as Human Resources, Marketing or Public Relations, thus reinforcing the strong gendered horizontal segregation. Very few instead elect for roles in Research and Development, Technical Development or Finance \& Controlling, divisions where the management talent pool is selected.

Whereas interventions striving to achieve more gender equality have been introduced in the industry for more than two decades, mainly under the continuous interactions with the trade unions, the integration of women into the male dominated units and the gendered hierarchy show little impact on the deep anchored gender discrimination practices (Kurz, 2006).

Kurz indicates a double sided trend in the automotive industry; namely a rampant precarisation and an academisation of women's employment patterns which impede the design and implementation of efficient gender equality measures. In addition, due to the low number of female employees viewed as "quantité négligeable" in the sector, there is little incentive for the automotive organisations to engage in change.

\section{Methodology}

The present German company was selected for it prides itself on having a good equal opportunity policy to investigate how men and women are faring in this best practice company.

For this purpose, a qualitative case study approach comprising the analysis of company documents and semistructured interviews was used for it takes into account the social context surrounding the phenomenon under study (Fagenson, 1993; Stake, 2000; Yin, 2009; Waylen, 2014). Thereafter, the case study enabled the deep dive into the context and the object of study, contributing to a holistic understanding of gender equality dynamics within its social context (Stake, 2000; Yin, 2009).

The goal of the company document analysis was twofold: (1) to draw organisational practices within their context; (2) to describe, classify and analyse the various corporate policies. Company documents were divided into the following categories: Yearly review comprising quan-

\footnotetext{
${ }^{2}$ Audi, BMW, Daimler, Opel, Porsche, Volkswagen

${ }^{3}$ Frauenbeschäftigung in der Automobilindustrie (Chancengleichheit, März 2012)
} 
titative data on personnel situation and repartition, vision and strategy statement of the company, gender diversity/ equality reports and booklets of the case company.

Some of these documents were openly accessible through the companies' website, while some were granted after informing the companies HR chief officer of my intention and research project and upon agreeing a confidentiality and anonymity clause. Therefore all information related to the identification of the studied organisations are removed from this paper.

While the study took place between 2012 and 2015, some of the data collected in particular quantitative reports stretches within the time frame 2010-2013 enabling thus to track change over a longer period of time.

In addition, all this material was to be read together with the governmental and trade union regulations and cartel agreements on the respective national and regional levels to which the case companies had to submit. The above named documents are designated as supplementary documents.

For the analysis of company documents, Ely and Meyerson's fourfold framework was utilised together with Rao and Kelleher's quadrants as explained earlier. This analytical tool enabled not only the understanding of gender equality schemes mechanisms but also the identification of areas of change.

Furthermore, the field study generated data based on semistructured interviews addressed to 13 participants, female and male executives from 28 to 59 years across the managerial hierarchies (see Figure 2. description of interview participants).

The interview guideline was conceived in order to seek for subjective views rather than absolute truths, in other words, the goal of the interview was to find out how people perceive the organisational interventions, how they talk about and which meaning they attribute to it (Rubin Rubin, 2011). The main questions were designed to focus on the substance of the research problem and broken down into two major blocks thematising and addressing the research puzzle formulated as follows:

(1) According to your own experience and career path, is the management in your company gendered? How may gender influence/have influenced (or not) managerial careers and advancement?

(2) How do you perceive and experience the Equal Opportunity Policies (EOP) and other voluntary programs aimed at increasing women's representation at management level in your company?

The interview guideline addressed to HR officers varied slightly from the standard interview guideline for that the focus of the questions was set on EOP and women advancement programs only.

The data was analysed using Ritchie and Lewis's (2003) qualitative analytic hierarchy as a guide. The aim was to highlight managers' own stories of equal opportunity and career advancement thereby increasing our understanding of how individuals view and experience gender equality and gender relations in a particular organisational setting.

\section{Research findings}

In the following section, the main findings of the study are presented. First, the gender policies in the German case company are mapped and analysed, second the perceptions and experiences of male and female managers are analysed and interpreted.

\section{Mapping the gender policy: Equal opportunity and women}

The German automotive company primarily applies two types of measures corresponding to what Ely and Meyerson (2000) call "Equal Opportunity" and "Fix the Women" constituting the bulk of the gender equality pledge in the company (see Figure 3. Mapping gender policies in the German company). The German company showed particular pride for having inscribed equal opportunities statements and policy in its strategy of development since the 1990's. This is an important information as before the introduction of the gender quota in 2016, a company in Germany was not enforced to comply with any gender related legislation, but only encouraged; companies were invited to promote gender equality only on a voluntary basis. Therefore the German auto maker had set officers within the Human Resources Management with responsibility for managing various aspects of equal opportunities (not only gender diversity). The major trade union active in the organisation acts as counter power and monitoring tool, issuing regularly reports on advancements in terms of gender equality, in particular closing the gender pay gap.

\section{Equal opportunity}

Gender in the German automotive company is still largely framed as difference between men and women; these differences result from differential structures of power and opportunity that block women's advancement (Ely - Meyerson, 2000). Management overwhelmingly remains a men's arena. Women fill only $10 \%$ of the overall managerial positions. The largest proportion of women is concentrated in the lower management level with $10 \%$, while high and top management comprise respectively only $8 \%$ and $5 \%$ of women.

As mentioned earlier, gender based discrimination alongside ethnicity, age and disability are ruled out by the concepts of "Gleichstellung": equal positioning and "Chancengleichheit": equal opportunity. The central objective of this approach adopted by the case company is to create equal opportunity for minority categories by eliminating discriminatory structural and procedural barriers.

Under the frame "Equal Opportunity", the documentary analysis located the implementation and monitoring since 2014 of voluntary differentiated targets to increase the proportion of female apprentices, female skilled workers, female graduates and professional recruits and female executives.

The above mentioned affirmative actions are complemented by revised recruiting and selection procedures. For instance, no internal or external job application is handed personally or directly to the concerned business unit, but managed over a central database by the Human Resources Management. The Human Resources Management has also set transparent promotion policies aiming at making requirements more "neutral" so that women are more likely to be in the same situation and thus qualified for equal treatment. 
These are the building blocks of the so-called "meritocratic system", based on supposedly objective criteria of education, experience and skills; it suggests the application of "fairness" at work.

Within the "Equal opportunity" frame, work reconciliation policies are supposed to ensure a family friendly workplace. These initiatives allow substantial flexibility in relation to hours of work, offer an extensive range of parttime and shift working arrangements, guarantee a return to work at the same level after parental leave and support childcare either within or near the company premises and expands childcare provision. Whereas the company measures to combine work and family responsibilities are addressed to both male and female employees, the majority of employees taking advantage of these policies remain women. This can be partly explained by the gendered role culture and the lack of child care infrastructure in Germany as mentioned in earlier parts.

In addition, when looking at the ranking of female employees (not to talk about men) taking advantage of these benefits, data indicate that women in management resist using these flexible work benefits.

After having described the main components under the identified frame "Equal Opportunity", the results highlighted in the figure indicate that these measures impact the systemic and formal areas only. Rather than making changes, the policy under this frame tends to leave the basic gendered structure and processes of the German company untouched. Taking the institutional factors into account it appears that the "seemingly gender neutral" bureaucratic and organisational structure in the German company maintains not only the persistent patriarchal structure in such a male dominated organisational setting but also the anchored and invisible informal institutions (Acker, 1990; Wajcman, 1998).

\section{Fix the women}

The second pillar of the gender equality schemes in management in the German company is what Ely and Meyerson call "Fix the Women" initiatives or women advancement programmes. The objectives of this programme is to remove the individual barriers impeding women's ability to advance in management. The main rationale behind this measure is to equip women with the necessary skills to play the game or "Spiele der Macht". Stemming from the liberal strain, the goal of "Fix the women" is to minimize differences in experience and academic and business socialization between women and men so that women can compete as equals in management (Fletcher - Ely, 2003; Ely et al., 2011). Within this frame, organizational interventions' sole targets are women. The programme stretches over a 9-month period. After the completion of various seminars, internal projects and under the supervision of a female mentor, the mentee-women identified as management talent gain a so-called by-pass leading them straight to the management pipeline. From its creation two decades ago until 2014, 400 female employees have taken part in the programme (latest 60 participants in 2014). Content wise, the women-only development programme does not differ from the standard management programme that was established five years ago for all employees (multi-layered initiative incl. junior, international and senior managers' development programmes).

Women in engineering programs and executive development programs represent the hallmark of this approach. Many women have learned valuable skills from these programmes. These efforts produce an enhanced applicant pool and create a pipeline of qualified women to fill management positions.

These interventions which are aimed at "fixing" or equipping" women are ameliorative strategies organisations typically use as a first response to difficulties in promoting and retaining women. However, the focus is on the individual level, not on changing the systemic factors within organizations and institutions that create an uneven playing field for women. Interventions within this frame may help certain women to "play the game" leaving existing organizational policies and structures intact and are meant to assimilate women with minimal disruption to the status quo (Ely - Meyerson, 2000b).

Based on Ely and Meyerson's (2000) model, the perspectives "Celebrate Differences" typically involving staff knowledge, awareness and commitment to gender equality, and "Revise Work Culture" which combat prevalent cultural norms and practices impeding gender change are not constituent part of the gender equality schemes in the German company. As Waylen (2014) argues the enforcing of institutional formal change cannot bring about long-lasting effects if the deep und unspoken informal rules are not tackled in the same way. These areas of intervention remain untouched and intact in the German company. Hence, the deep structure or taken for granted values, ways of thinking and working that underlies decision-making and action is largely unexamined and gender biased in the case German company.

As Acker (1990) pointed out, the key assumption in large organisations is that work is completely separate from the rest of life, and the organisation has first claim on the worker. From this follows the idea of the "ideal worker" dedicated to the organisation. Despite the extension of equal opportunities measures based on work life reconciliation benefits, this essential assumption is maintained. Women in the German company take advantage of these benefits, having thus more often breaks in their career, and juggling between professional and household duties, while men do not and pursue a linear career evolution.

\section{Perceptions of male and female managers: towards a re-configuration of gender relations in organisation}

In the following section, key insights retrieved from the interviews of male and female managers (incl. HRM chief officer) in the German company are presented and structured according to the main research questions.

\section{Car's world, Men's world}

When asked about gender relations in their company, and in particular in management, in a remarkable majority 
of the interviews, the basic hierarchical male dominated form of organisation is taken for granted in the company. Gendered hierarchy and gender asymmetry are considered normal and as such is taken for granted, being presented in an anodyne and straightforward manner. There is one thing; in general, many men work in the automotive industry, which explains why there are more men in management than women. (R. Man in middle management).

By way of explanation to the question - why are so few women in the industry and in the managerial positions both male and female managers pointed out the lack of interest from women in entering technical studies or professions:

I think also that there are just few women who are interested in and decide to make career in these fields. For example, more than $80 \%$ of our applicants and interns are men. (S. woman in lower management). Patriarchal gender order and masculine norms are thus constructed and maintained through a deep entrenched gendered discourse. Both male and female managers locate the problem at the level of women rather than at the level of the processes in the workplace. These expectations expressed by the participants shows how the masculine norm is widely accepted and taken for granted, it is normal or typical for the automotive industry.

\section{The company does too many programmes!}

With regards the question -how do you perceive gender equality measures in your company?- most of the responses suggested that the interviewees had little information about the gender equality and women advancement programs in place in their companies? Their responses were characterised by a confused and rather vague knowledge about fragments of policies. This poor knowledge or contact with the issue of gender equality interventions even at the highest level of management, strongly contradicts the company policy statements and supposedly strong gender mainstreaming process. Gender equality issues are not only at the margins of male and female managers' agenda, but considered as obsolete:

The Company does just too many things, too many programmes, it is confusing and a waste of money. (Y. man in top management)

Such narratives point to what Kelan (2009) describes as gender fatigue, both male and female managers do not prioritise gender discrimination as workplace issue, but dismiss it, at best as a solved issue and at worse as an individual deficiency.

Instead, both female and male managers stressed the existence and the paramount importance of standard management training and advancements programs with a detailed description of the step by step process involved. These management programmes are often designed against a masculine norm of managing, relying on the ideal worker assumption. The narratives around these programmes show that these "neutral" programmes are the sole reference for career-making in management, they are in the German organisation socially acceptable: I haven't heard of these women programs. I have somehow heard something that should happen sometime, but no one talked about it with me. (S. woman in lower management).
These discourses show that informal rules such as masculine values and practices in management maintaining the subtle gender bias are well anchored and internalised among the participants. They do not only display signs of gender fatigue but firmly believe in merit and fairness in their company.

Likewise, female managers rejected the interventions aimed at women only, in particular gender quotas: I did not take part to any sort of women advancement program and consider this whole story as bullocks. We talked about with my supervisor at that time and said how ridiculous it was. (T. Woman in high management)

I never thought that I had problems that I need more support because I am a woman in management! There are other women in the division in the same situation and they don't take part of these, they all share my opinion. (S. woman in lower management).

These clear statements show two strong yet contradictory tendencies: on the one hand, the fear of feminine stigmata may lead to an eventual polarisation of relations among women and in-group tension. This contributes to the maintenance of the "individual woman as a problem". The status quo in relation to gendered hierarchies in the organisation remains untouched. On the other hand, women continue to construct their work identity against the mirror of male values. In addition, these statements highlight the tension and mismatch between employees needs and HRM responses.

Male managers unanimously rejected any forms of affirmative actions. They do not include themselves as actors in the gender debate, rather as passive observers although they possess a substantive knowledge about gender (in)equality in the workplace. They rather identified themselves as victims and showed resentment: It is unfair, ok women have several disadvantage in the organisation, but the problem lies somewhere else. Why men should be penalised and women shall get the straight line to management. (F. men in middle management).

In addition, both male and female managers stressed the importance of voluntary interventions. They typically expressed the need to empower girls and young women at an early stage to enter technical education and careers within the automotive sector. According to them, interventions at an early age and more generally outside the company and providing a higher visibility of feminine role models are key actions.

\section{The critical role of the Gender Diversity Chief Officer}

Hearn et al. (2010) in their study of the discourses of managers in several Swedish firms about gender equality argue that Human Resources officers play a crucial role in expanding, translating and bringing gender equality understanding and application to life in their organisations. The interview conducted with the Gender Diversity/Women Advancement Chief Officer in the German company could shed light on how the issues of gender in management, particularly on how the notion and challenges of gender equality are conceptualised and discursively formulated. The data collected offers complementary insights to the document analysis results discussed in earlier parts. 
In the German company, the Gender Diversity/Women Advancement Chief Officer belongs to the department Human Resources but reports directly to the executive board of management. She has no responsibility for the larger workforce; she is the sole responsible person for all issues related to gender diversity, with a specific focus on women in management. (Women at the lower levels and production lines being tacitly supported by the trade union instead.) The Chief Officer held a discourse characterised by pride about the progress done in the last years.

We can be proud of our performance, never before women were so powerful in the group. Let's continue the good job.

On the one hand, she acknowledged the challenges encountered by women on their way to management, underlining the stereotypes and gender beliefs prevailing in the company. She however imputed these barriers largely to the technical dimension of the industry, rather than locating the issue in the very structures of the organisation. On the other hand, she defended strongly the measures undertaken, underlined the high instances of management involvement, and most importantly did not question the sense and success of the programmes in place.

Our board asks for change and stands fully behind the advancement of women in management. Our mix of actions bring results.

Her discourse focused on the number of women who participated in the women's advancement programmes, on prominent names of managers who endorsed the programme and the prizes and awards offered to women engineers.

For example, last week I attended the delivery of awards for best women engineers...

When asked about what could still be done and in which directions the programmes are directed, the Chief Officer, stated that the objective is to over meet the quota and continued with this line of argument:

Target is to continue to increase the number of women accessing the management, up to $30 \%$

At last, when asked which measures according to her are the most effective and important, she replied that encouraging young women to study engineering and targeting young female graduates are the most important interventions. She thus did not question the structural and cultural arrangements of the company, but highlighted the preferences and choices of girls and young women as the key change area.

As a matter of fact, the Gender Diversity/Women Advancement Chief Officer displayed a very normative view on the interventions, typically top-down designed. Her approach embraces the logic of affirmative action, which aims at increasing the number of women in management and largely locates the gender asymmetry within women attitudes, choices and preferences. The armada of measures to support women in this journey (see mapping of company policies) does not question or challenge the deeply entrenched gendered structures and practices. The measures are "window-dressing" actions focusing on a certain segment of women; namely white, young graduates, and academics. The cultural assumptions underpinning the under representation of women in technical fields and in management are not addressed. In this sense, the views and perceptions of the Gender Diversity/Women Advancement Chief Officer correspond to the persona of a gatekeeper, disguised as being "corporate social responsible" and "committed" but defending the actual status quo.

The group is a very social group, it offers many options for women working here, and we make sure the most talented gets into the management.

\section{Conclusions}

Drawing from a case study in a German automotive company making use of an innovative combination of two analytical frameworks elaborated by Ely and Meyerson (2000) Rao and Kelleher (2005), this article attempted to contribute to the understanding of the dynamics of gender equality in organisation, and in particular in management. Contending that gender policies are a contextualised product (Radjavi, 2012), it highlights the unintended effects of gender equality schemes in management in the selected German automotive company, by examining the macro-, meso- and micro levels. Doing so, the study offers a holistic view on the issue of gender equality change in organisation.

The study results shows that gender inequality in management in the German company stretching over a decade is still based on the idea of sameness and neutrality and ignores the effects of structural and gender inequalities (Liff - Wajcman, 1996).

The main shortcomings of the gender equality programmes implemented are identified. The gender equality schemes maintain and perpetuate the unequal gender order. Instead of dismantling the gender status quo, they are in continuity. Following the principle of neo-liberalism, women are massively added on the existing contemporary patriarchal system (Wajcman, 1998) and the target of all the interventions remains mainly women. The corporate approaches categorised as "Fix the Women" according to Ely and Meyerson's (2000) framework, have brought mediocre gains since their implementation in the German company (from 1999 until today). They have enabled only a limited number of women to enter managerial functions. The recent introduction of differentiated targets has intensified the process of raising the women's numerical representation. However, in line with the German governmental and legal measures, work life reconciliation benefits under the "equal opportunities" frame are one sided and focus in particular on motherhood/parenthood and are still widely used by women only.

Hence, these findings support the previous research (Wajcman - Liff 1996; Ely et al., 2011, 2010; HanappiEgger, 2012; Ely - Meyerson 2000; Kelan, 2009, 2013) stating that most of organisational measures rather than addressing the hidden structures reinforce the gendered substructures. Following this line of argument, it can be stated that the combination of "Fixing the Women" and "Equal Opportunities" frames, in particular with the recent introduction of gender quota unleashed a wave of tacit protestation and resistance from both interviewed groups, male and female managers.

Indeed, the interviews results provided insightful information as regards the research questions. 
(1) According to your own experience and career path, is the management in your company gendered? How may gender influence/have influenced (or not) managerial careers and advancement?

The strong technical and industrial dimensions of the organisational culture (long working hours, face time working style, male codes and mind-sets) were viewed by both men and women as the main cause explaining the paucity of women in managerial positions. The lack of interest of women for pursuing a career in the automotive sector was pointed out to explain the strong gender bias and the striking horizontal segregation across divisions. As a result, female participants conceal and often deny the longstanding and deeper effect of gender bias in their workplace. This form of legitimacy of gender inequality in management is central to female managers' account and experiences in the German company. Although numerical underrepresentation of women in managerial ranks is well recognized and thus a visible fact of the German organisational life, gender based inequities as the root cause of this imbalance remains invisible. . Female participants were often reluctant to locate gender disadvantage within the gendered organisational regimes (Lewis - Simpson 2010). Taken for granted views on engineering and differential roles, capabilities and expectations between men and women are key constituent of women's managerial experiences.

(2) How do you perceive and experience the Equal Opportunity Policies (EOP) and other voluntary programs aimed at increasing women's representation at management level in your company?

Experiences and accounts of male managers on gender equality show that they strikingly resist and perceive any interventions as unfair advantage for women. This study shows that men in the German company are not aware of the gender imbalance, they overtly disregard organisational measures aiming at promoting women. This points towards the lack of consideration for gender equality issues in the managerial ranks in the German company. Male participants adopt a language of individual choice to explain gender based disparities in career outcomes. In this context the responsibility for equality and fairness is removed from the remit of the organisation and mostly from the managerial man. The presented findings clearly supports Wajcman's (1998) notion of resistance and resentment on the side of men. The gender equality frameworks fail to give a voice to men without reinforcing their privilege and their centrality which is reflected in their continuing dominance in senior and engineering positions in the automotive sector.

This study thus bears significant implications for further research for it shows how the equal opportunity policies and the rhetoric of gender justice draw attention away from continuing disadvantage and privilege. The proposed analytical framework is not only a documented witness but also a promising tool for practitioners and researchers.

The qualitative study per se lacks generalisability criteria; the results are driven from a particular sector and industry, and highly contextualised. Whereas the findings are local, they offer a deeper insight into a complex phe- nomenon, that still nowadays puzzle scholars and practitioners. The multiple case study presented following a rigorous analytical "template" is replicable, the variety of methods used reinforced the internal as well as the external validity, so that the procedure although time consuming can be replicable and verifiable by other parties.

Further research is therefore needed to dismantle the mechanisms of informal rules, such as the activities of networking and mentoring. Cross cultural and cross sectorial studies might shed light on the complex interplay between institution, structural and organisational factors when designing gender equality schemes.

Further work using the innovative conceptual and analytical tool presented in the study earlier can and should be conducted in other industries, for instance, a cross-sectorial study could pinpoint fine-grained similarity or differences. Moreover, cross cultural strategy using the same framework and comparing for instance third world and post-industrial societies could offer fine-grained insights to understand to which extent company culture plays a role and how the cultural and institutional framework shapes the meanings given to gender equality measures.

\section{References}

Acker, J. (1990): Hierarchies, Jobs, Bodies: A Theory of Gendered Organizations. Gender and Society, 4, pp. 139-158. Acker, J. (1992): From Sex Roles to Gendered Institutions. Contemporary Sociology, 21, pp. 565-569.

Acker, J. (2006): Inequality Regimes: Gender, Class, and Race in Organizations, Gender and Society, 20(4), pp. 441-464.

Acker, J. (2010): Geschlecht, Rasse und Klasse, die Untersuchung von Ungleichheit aus der Perspektive der Intersektionalität.

Calás, M. - Smircich, L. (2006): From the "woman's point of view ten years later: towards a feminist organisation studies. In: Clegg, S. R. - Hardy, C. - Lawrence, T. B. - Nord, W. R. (eds.): The Sage Handbook of Organisations Studies. London: Sage, p. 284-346.

Calás, M. B. - Smircich, L. (2009): Feminist Perspectives on Gender in Organizational Research: What Is and Is Yet to Be. In: Buchanan, D. - Bryman, A. (eds.): The Handbook of Organizational Research Methods. London: Sage, pp. 246-269.

Catalyst (2018): Quick Take: Women in the Automotive Industry, Available at: https://www.catalyst.org/research/ women-in-the-automotive-industry/\#footnote19 h0yrecc (Accessed 24 February 2019).

Connell, R. W. (2002): Gender. Cambridge: Polity Press; Malden: Blackwell Publishers.

Cooke, L. P. (2007): Persistent policy effects on gender equity in the home: the division of domestic tasks in reunified Germany. Journal of Marriage and Family, 69 (4). pp. 930-950.

Doldor, E. - Vinncombe, S. (2015): Women's pathways to the boardroom. Gender in Management: An International Journal, 30(7), pp. 523-550.

Ely, R. J. - Ibarra, H. - Kolb, D. (2011): Taking Gender into Account: Theory and Design for Women's Lead- 
ership Development Programs. Academy of Management Learning \& Education

Ely, R. J.-Meyerson, D. E. (2000): Theories of gender in organizations: A new approach to organizational analysis and change. Research in Organizational Behavior, 22, p. 103-151.

Fagenson, E. A. (1993): Diversity Management Introduction. Women in Management: Trends Issues and Challenges in Managerial Diversity. In: Fagenson, E. A. (ed.). (1993): Women and work: A research and policy series, Vol. 4. Women in management: Trends, issues, and challenges in managerial diversity. Thousand Oaks, CA: Sage Publications, Inc., pp. 3-5.

Fagnani, J. - Math, A. (2007) : Les récentes reformes de la politique familiale en Allemagne : de nouveaux horizons pour les femmes ? Droit Social, 5, p. 630-636.

Fletcher, J. K. - Ely, R. J. (2003): Introducing Gender: Overview. In: Ely, R. J. - Foldy, E. G. - Scully, M. A. (eds.): Reader in Gender, Work and Organisation. New York: Wiley Blackwell, pp. 3-9.

Gherardi, S. - Poggio, B. (2007): Gender telling in Organizations: Narratives from Male Dominated Environment. Copenhagen: Liber

Hanappi-Egger, E. (2011): The Triple M of Organisations: Men, Management and Myth. Vienna, New York: Springer

Hanappi-Egger, E. (2012): "Shall I stay or shall I go"? On the role of diversity management for women's retention in SET professions. Equality, Diversity and Inclusion: An International Journal, 31 (2), p. 144-157.

Hanappi-Egger, E. - Eberherr, H. (2016): Routinierte Vergeschlechtigung: Zur (Re-) Produktion von Geschlechttypisierungen und impliziten Rollenerwartungen im Management. Managementforschung, (25), pp. 115-138.

Hearn, J. - Husu, L. - Lämsä, A. M. - Vanhala, S. (eds.) (2010): Leadership through the Gender Lens: Women and Men in Organizations. Helsinki: Edita

Hearn, J. (2012): Role of Men in Gender Equality: Study on the Role of Men in Gender Equality. In: Scambor, E. - Wojnicka, K. - Bergmann, N. (eds): Final Report to the European Commission. VC/2010/0592. Vienna: L\&R Social Research

Holst, E. (2010): Institutionelle Determinanten der Erwerbsarbeit: Zur Notwendigkeit einer Gender-Perspektive in den Wirtschaftswissenschaften. Discussion papers of DIW, Berlin

Holvino, E. - Kamp, A. (2009): Diversity management: Are we moving in the right direction? Reflections from both sides of the North Atlantic. Scandinavian Journal of Management, 25(4), pp. 395-403.

Kelan, E. K. (2009): Gender fatigue: The ideological dilemma of gender neutrality and discrimination in organizations, Canadian Journal of Administrative Sciences/ Revue Canadienne des Sciences de l'Administration, 26 (3), pp. 197-210.
Kelan, E. K. (2013): The Becoming of Business Bodies: Gender, Appearance, and Leadership Development. Management Learning, 44 (1), pp. 45-61.

Kurz, C. (2006): Zwischen Prekarisierung und Akademisierung: Frauenerwerbstätigkeit in der Automobilindustrie. SOFI Mitteilung, 34, pp. 53-66.

Lewis, P. - Simpson, R. (2010): Revealing and Concealing Gender: Issues of Visibility in Organizations. Basingstoke: Palgrave Macmillan

Liff, S. - Wajcman, J. (1996): "Sameness" and "difference" revisited: which way forward for equal opportunity initiatives? Journal of Management Studies, 33, pp. 79-94.

Meyerson, D. E. - Kolb, D. M. (2000): Moving out of the "armchair": Developing a framework to bridge the gap between feminist theory and practice. Organization, 7(4), pp. 553-571.

Rao, A. R. - Kelleher, D. (1999): Gender at work: Organisational Change for Equality. West Hartford, Connecticut: Kumarian Press, Inc

Rao, A. - Kelleher, D. (2003): Institutions, Organisations and Gender Equality in an Era of Globalisation. Gender and Development, 11(1), pp. 142-149.

Rao, A. - Kelleher, D. (2005): Is there life after gender mainstreaming? Gender and Development, 13(2), pp. 57-69.

Ritchie, J. - Lewis J. (2003): A Guide for Social Science Students and Researchers. London: Sage

Rubin, H. J. - Rubin, I. (2011): Qualitative Interviewing: The Art of Hearing Data. Thousand Oaks: Sage Publications

Stake, R. (2000): Case Studies. In: Denzin, N. K. Lincoln, Y. S. (eds): Handbook of qualitative research. Thousand Oaks, CA: Sage, pp. 435-454.

Tatli, A. - Vassilopoulou, J. - Al Ariss, A. - Özbligin, M. (2012): The Role of Regulatory and Temporal Context in the Construction of Diversity Discourses: The case of UK, France and Germany. European Journal of Industrial Relations, 18(4), pp. 293-308.

Wajcman, J. (1996): Women and men managers: careers and equal opportunities. In: Crompton, R. - Gallie, D. - Purcell, K. (eds) (1996): Changing Forms of Employment: Organisations, Skills and Gender. London: Routledge, pp. 259-277.

Wajcman, J. (1998): Managing like a man: women and men in corporate management. Cambridge: Polity Press in association with Blackwell Publishers Ltd.

Waylen, G. (2014): Informal Institutions, Institutional Change and Gender Equality. Political Research Quarterly, 67(1), pp. 212-223.

Weinkopf, C. (2014): Women Employment in Germany: Robust in Crisis but Vulnerable in Job Quality. Revue de l'OFCE, (133), pp. 189-214.

Whitehead, S. (2002): Hegemonic Masculinity Revisited, Gender. Work \& Organization, 6 (1), pp. 58-62. 